\title{
Patrimônio arqueológico da Serra da Moeda, Minas Gerais: uma "unidade histórico-cultural"
}

Luana Carla Martins Campos*

\section{Resumo}

Baseado em resultados das pesquisas do projeto "Levantamento e Avaliação do Potencial Arqueológico da Serra da Moeda e Entorno", relacionado ao processo de tombamento estadual deste conjunto urbano e paisagístico, este texto busca contextualizar, quantificar e qualificar o patrimônio arqueológico existente no maciço da Serra da Moeda em Minas Gerais. Salienta-se que o ambiente possui vestígios de ocupação humana pré-histórica e histórica, sendo esta datada a partir de fins do século 17, em função da exploração das jazidas minerais no contexto do denominado "Ciclo do Ouro". Cumpre-se ressaltar que a colonização das diferentes partes da Serra e de seu entorno não se fez de maneira estanque, mas integrada, de modo que se deve considerar a região em análise como uma grande unidade expressa na conexão entre suas partes. Tal integração foi produto do processo histórico-cultural evidenciado por meio do conjunto de seus vestígios arqueológicos.

Palavras-chave: Patrimônio cultural. Tombamento, Serra da Moeda, MG. Patrimônio ambiental.

\section{Archaeological heritage of the Serra da Moeda, Minas Gerais: a "historical and cultural unity".}

\section{Abstract}

Based in gotten results of the research carried through the project "Survey and Evaluation of the Archaeological Potential of the Mountain range of Moeda and Around", to the process of state legal protection of this urban and natural set, the work searchs to contextualize, to quantify and to characterize the existing archaeological heritage in the bulk of the Mountain range in Minas Gerais. Salient that the environment possesss occupation vestiges prehistoric and historical human being, being this dated from ends of century 17 , in function of the exploration of the mineral deposits in the context of the called "Cycle of the Gold". It is marked to stand out that the settling of the different parts of the Mountain range and its around did not 
become in way stanches, but integrated, in way that if must consider the region in analysis as a great express unit in the connection between its parts. Such integration was product of the evidenced description-cultural process by means of the set of its archaeological vestiges.

Key-words: Cultural heritage. Legal protection, Serra da Moeda, MG. Cultural environment.

\section{Apresentando a região e algumas das diretrizes que nortearam a elaboração} do laudo para o tombamento estadual do patrimônio natural e cultural da Serra da Moeda/MG

O projeto "Levantamento e Avaliação do Potencial Arqueológico da Serra da Moeda e Entorno" integrou o estudo elaborado no ano de 2008 para o processo de tombamento estadual desta região de Minas Gerais visando a proteção legal do patrimônio cultural existente nesta área. Trata-se de uma cadeia de montanhas pertencente ao grupo do Complexo da Serra do Espinhaço e insere-se no chamado Quadrilátero Ferrífero, área que se destaca no cenário geológico mundial pelas abundantes riquezas constantes em suas reservas de minérios, a exemplo do ferro, ouro, alumínio, manganês e topázio.

Do ponto de vista geológico e geomorfológico, a Serra da Moeda faz parte da região conhecida por Sinclical de Moeda. Trata-se de um conjunto de ambientes montanos - nitidamente distinguível na paisagem regional - formado pela Serra da Moeda, Serra das Serrinhas, Serra dos Três Irmãos, Serra do Esmeril, dentre outras. No caso da Serra da Moeda, seu território corresponde às formações geológicas chamadas de Moeda e Cauê que são conexas às altitudes superiores a 1.400 metros, enquanto cotas inferiores associam-se principalmente à Formação Gandarela. Neste aspecto, tais limites foram utilizados como balizas à individualização e delimitação da área da Serra da Moeda em relação ao restante de sua Sinclical, de modo a tomar a cota de 1.100 metros de altitude como uma referência média. Historicamente, todavia, a região conhecida por Serra da Moeda abrangia um território bastante extenso e difuso nas paragens das Minas Gerais localizada entre as bacias dos rios Paraopeba e das Velhas. 
De modo geral, a Serra da Moeda é uma região que apresenta gradientes altitudinais acentuados, constantes de áreas de cristas, cumes e picos. Em sua vertente ocidental, atinge o vale do Alto Rio Paraopeba, enquanto sua porção nordeste compreende o Alto Rio das Velhas, ambos cursos d'água afluentes da margem direita do Rio São Francisco. Abrangendo os limites dos biomas da Mata Atlântica e do Cerrado em uma área de $240 \mathrm{~km}^{2}$, a Serra da Moeda estende-se pelos territórios de oito municípios mineiros localizados na Região Metropolitana de Belo Horizonte, a saber: Belo Vale, Brumadinho, Congonhas, Itabirito, Moeda, Nova Lima, Ouro Preto e Rio Acima.

Segundo as atuais convenções sobre desenvolvimento sustentável e meio ambiente, esta região constitui um ecossistema frágil, uma vez que é fonte de provimento dos recursos fundamentais à vida dos homens, como é o caso dos mananciais, minérios, produtos florestais e agrícolas. Estas foram apenas algumas das questões que incentivaram e nortearam a elaboração de um dossiê de tombamento visando a salvaguarda do acervo natural e cultural da Serra da Moeda/MG (SOLÁ; GUIMARÃES; PAIVA, 2008). Tendo como objetivo principal a preservação da diversidade do patrimônio da região, o estudo foi realizado com o patrocínio do Sindicato da Indústria Mineral do Estado de Minas Gerais (SINDIEXTRA) e da Federação das Indústrias do Estado de Minas Gerais (FIEMG), ficando a cargo da empresa BRANDT Meio Ambiente a consolidação do relatório final. No tocante à arqueologia, esta pesquisa ficou sob a responsabilidade do Prof. Dr. Carlos Magno Guimarães.

Destarte, realizou-se um estudo pormenorizado que envolveu profissionais de distintas instituições e de diversas áreas do conhecimento, tais como biólogos, geógrafos, engenheiros ambientais, arquitetos, geólogos, historiadores, arqueólogos e turismólogos. As principais diretrizes que nortearam o laudo relacionaram o patrimônio cultural sob seus diversos ângulos, dentre eles a perspectiva histórica, arqueológica, ecológica, geológica-geomorfológica e arquitetônica, urbanística e paisagística, de modo a construir uma narrativa coesa e que demonstrasse a importância da região estudada. 
A princípio, dentre os principais resultados obtidos a partir deste laudo, tem-se o levantamento e sistematização de informações concernentes a variados campos do saber que, para a região objeto de análise, eram até então praticamente desconhecidas. Todavia, a escassez de inventários e de outros estudos mais sistematizados sobre a Serra da Moeda fortalece a permanência de inúmeras lacunas sobre a área o que causa consternação sobre a perda iminente do seu patrimônio. Por outro lado, tem-se ainda como relevante resultado decorrente deste laudo, a compreensão da necessidade de estudos pormenorizados e a proteção do patrimônio da região.

Esta realidade mostra-se inquietante em um contexto de crescente influência econômica por parte das empresas mineradoras e imobiliárias. Do ponto de vista da exploração mineral, a região é, ainda hoje, responsável por cerca da metade de toda a produção do Estado de Minas Gerais que, por sua vez, comanda os índices nacionais. Já no tocante ao setor imobiliário, o clima ameno e a beleza cênica de ambientes montanos próximos à capital mineira têm motivado, há décadas, a expansão urbana em direção a estas regiões, seja como vilas de casas de campo ou como condomínios luxuosos.

Faz-se urgente, portanto, ações de acautelamento legal do patrimônio cultural e ambiental da Serra da Moeda visando a sua salvaguarda. Neste contexto de embates entre a preservação e/ou progresso, busca-se o equilíbrio sensato entre estes extremos. Ambiciona-se a proteção dos bens patrimoniais com 0 aproveitamento sustentável dos recursos da região, de forma a promover a valorização e o uso adequado do seu patrimônio natural e cultural com respeito às corretas formas de uso e ocupação do solo.

A gestão da região da Serra da Moeda constitui um desafio que se apresenta ao setor governamental que deve buscar alternativas para uma integração efetiva entre as políticas ambientais, culturais e político-econômicas de sua administração. Mesmo constatando que, muitas vezes, a proteção legal não é condicionante para a preservação do acervo natural e cultural do país, os ecossistemas de montanhas devem ser tomados como prioridade nas iniciativas de desenvolvimento sustentável. Por outro lado, esta também é uma provocação que se coloca ao setor produtivo 
que precisa fomentar e desenvolver um planejamento estratégico de suas atividades que assegurem a conservação do acervo da região, especialmente se o processo de tombamento da Serra da Moeda for aprovado pela Assembleia Legislativa de Minas Gerais com sistematização do dossiê a ser realizado pelo Instituto Estadual do Patrimônio Histórico e Artístico de Minas Gerais (IEPHA/MG).

\section{Levantamento do patrimônio arqueológico da Serra da Moeda/MG: conceitos e metodologias}

Devido às limitações das dimensões deste artigo, não se faz necessária uma discussão exaustiva sobre o processo histórico de constituição do conceito de patrimônio. Importa-se, no entanto, tecer algumas considerações que sejam capazes de elucidar certas apreensões sobre o termo, bem como a respeito das definições contemporâneas sobre o patrimônio arqueológico.

$\mathrm{Na}$ concepção do historiador Michel de Certeau, ao contrário da cidade de Roma, "Nova lorque nunca aprendeu a arte de envelhecer exibindo todos os seus passados" (DE CERTEAU, 1994, p. 21). Toma-se tal assertiva para enfatizar a questão de que a valorização da produção cultural do passado é uma percepção daqueles que compreendem a historicidade das ações e dos valores humanos. Nem tudo o que atualmente é tratado como patrimônio foi sempre assim considerado. As apreciações e ações de acautelamento derivadas de sua definição foram responsáveis por ganhos e perdas significativas do acervo cultural da humanidade ao longo da história.

Deve-se ter em vista que a experiência da modernidade, momento de intensas e rápidas transformações vividas no mundo ocidental especialmente após a Revolução Industrial, mas fundamentalmente durante o século 19 e princípios do 20, foi decisiva para o julgamento daquilo que deveria ser guardado ou do que seria destruído. Em suas origens, os bens patrimoniais estiveram associados aos monumentos que invocavam e perpetuavam uma determinada memória oficial das grandes nações ou de seus homens excepcionais.

Nesta circunstância, os Estados Nacionais ficaram a cargo da seleção das principais referências que deveriam compor seus acervos. O que se entedia por patrimônio 
estava associado, fundamentalmente, ao que se qualificava como obra de arte, ou seja, referia-se a um conjunto de bens de natureza imóvel e móvel que eram de interesse público por seu singular valor arqueológico, etnográfico, bibliográfico ou artístico. No caso do Brasil, as efetivas ações destinadas à proteção do nosso acervo foram oficializadas com a fundação do Serviço do Patrimônio Histórico e Artístico Nacional (SPHAN) no ano de 1937. Neste momento, a ênfase do conjunto a ser resguardado recaiu sobre os edifícios e objetos artísticos provenientes, essencialmente, dos períodos colonial e modernista brasileiro.

Constata-se que esta caracterização modernista sobre o acervo patrimonial do Brasil, tributária da noção de obra de arte e, de certa forma, limitada à arquitetura e ao urbanismo, embasou a seleção dos bens a serem protegidos considerando-os como patrimônio histórico e artístico nacional. Apesar de certas limitações causadas pela exclusão de diversas outras formas de expressão da cultura brasileira, a exemplo do patrimônio imaterial, pode-se dizer que o acervo tombado pelo IPHAN constitui, ainda hoje, um importante conjunto que se manteve íntegro devido às ações de acautelamento legais impostas a eles.

Todavia, deve ser salientado o fato de que a ampliação do conceito de patrimônio foi o resultado de um debate que se arrastou por décadas e motivado por inúmeros fatores, como o processo de industrialização e desenvolvimento das cidades brasileiras, cujos núcleos urbanos passaram a alterar a sua tipologia e configuração espacial fundamentalmente a partir dos anos de 1950. A este respeito, Néstor Canclini sublinha que nos debates sobre a preservação do patrimônio, normalmente são sempre considerados como os inimigos dos bens culturais "os atuais processos de mudança e desenvolvimento urbano, a mercantilização, as indústrias culturais e o turismo". No entanto, o autor avalia ser relevante analisar estas "ameaças" como contextos, uma vez que não somente devemos aceitá-los "por serem as condições em que hoje os bens históricos existem, mas também porque contribuem para repensar o que devemos entender por patrimônio histórico e por identidade nacional" (CANCLINI, 1994, p. 95).

$\mathrm{Na}$ contemporaneidade, estas questões precisam ser problematizadas sob a lógica da transformação constante dos centros urbanos que passaram a ser analisados 
como núcleos dinâmicos. Neste contexto, as cidades não são mais consideradas como um organismo em evolução, tampouco são vistas como o resultado de um acúmulo de eventos históricos que determinaram a sua configuração. O fim último da conservação de seu acervo não são os bens culturais em si, mas os valores sociais agregados, seus diversos usos e funções sociais partilhados pela sociedade ao longo dos anos.

As mudanças de concepção sobre o patrimônio também são associadas ao alargamento do conceito de cultura. Fruto de uma discussão fomentada por diversos campos do saber ao longo de todo o século 20, como nos explicita Sandra Pesavento, a cultura é atualmente considerada como "um conjunto de significados partilhados e construídos pelos homens para explicar o mundo", ou "uma forma de expressão e tradução da realidade que se faz de forma simbólica". Admite-se, portanto, "que os sentidos conferidos às palavras, às coisas, às ações e aos atores sociais se apresentam de forma cifrada", de forma que se entende a cultura por uma acepção mais antropológica, como o encontro e a reprodução de valores, identidades, memórias e discursos. Sublinha-se que a ciência histórica bebeu a água das fontes de diversas Ciências Sociais durante todo o século 20 (PESAVENTO, 2008, p. 15).

$\mathrm{Na}$ atualidade, portanto, as interpretações sobre a cultura extrapolam a perspectiva nacional devido, em grande medida, ao contexto da globalização que torna aquelas referências desterritorializadas, múltiplas e mais complexas, seguindo os compassos da economia neoliberal. Há um deslocamento da ênfase no estudo da cultura nacional - que na modernidade se constituiu como uma das principais fontes de identidade cultural - de modo a passar a focalizar parâmetros baseados nas comunidades locais. Tal dinâmica se explica porque a globalização representa processos

[ ] atuantes numa escala global, que atravessam fronteiras nacionais, integrando e conectando comunidades e organizações em novas combinações de espaço-tempo, tornando o mundo, em realidade e em experiência, mais interconectado. (HALL, 2006, p. $67)$. 
Desprovido do sentimento de identificação nacional, o sujeito cosmopolita e multifacetado na diversidade do mundo globalizado passa a experimentar uma profunda sensação de perda subjetiva. Há uma contradição latente entre a assimilação do universal através do contato com diversas culturas que extrapolam os limites das comunidades, e a simultânea adesão ao particular em um movimento pendular e contraditório entre o universalismo através do particularismo e do particularismo através do universalismo.

Nestas circunstâncias, as comunidades manifestam-se como agentes decisórios na definição do que se considera por patrimônio. Novos grupos culturais tornam-se visíveis no cenário social, buscando afirmar suas identidades e questionando a posição privilegiada dos grupos hegemônicos. A nação não é vista apenas pelo prisma da homogeneidade, mas pelo seu conjunto de diferenças e multiplicidades presentes em seu território. Estabelece-se, portanto, a valorização das referências culturais locais, de natureza material e imaterial, com o intuito de buscar o conhecimento de uma história atenta às diversidades e visando também a constituição de uma cidadania cultural.

O patrimônio, que antes contemplava apenas o acervo histórico e artístico nacional, ampliou seu espectro para todas as expressões culturais produzidas pelo seu povo. Arruinou-se a visão clássica de distinção entre a cultura dita erudita e a popular, sendo esta anteriormente avaliada como o reduto do autêntico. Retomando Canclini, este autor esclarece que o patrimônio cultural passa a representar o que um determinado

[ ] conjunto social considera como cultura própria, que sustenta sua identidade e o diferencia de outros grupos - não abarca apenas os monumentos históricos, o desenho urbanístico e outros bens físicos; a experiência vivida também se condensa em linguagens, conhecimentos, tradições imateriais, modos de usar os bens e os espaços físicos. (CANCLINI, 1994, p. 99)

Assim, na medida em que as próprias noções de história e cultura se modificaram, o conceito de patrimônio adquiriu outras perspectivas de forma a valorizar todos os atores da sociedade em seus diversos modos de vida. Estas mudanças de paradigmas trouxeram consigo, portanto, a discussão sobre como e de que maneira 
o conjunto de referências que identificam e definem uma comunidade devem ser salvaguardados. Neste ínterim, sublinha-se que as discussões fomentadas sobre esta temática constam em variados documentos normativos, a exemplo das Cartas Patrimoniais e da Constituição Brasileira de 1988 (Cf. Art. 216), que indicam os caminhos de identificação e preservação do patrimônio.

Atualmente, consideram-se como integrantes do acervo cultural os bens de natureza tangível e intangível, material e imaterial, que não foram produzidos apenas durante o período colonial ou modernista brasileiro. Procura-se não privilegiar os bens originários de classes hegemônicas ou subalternas, pois se reconhece que o patrimônio de uma comunidade nacional ou local se compõe por uma cultura multifacetada e polivalente. Mesmo com suas limitações derivadas dos processos de seleção, forma-se um conjunto que procura refletir a realidade híbrida e múltipla dos diversos grupos existente no Brasil através da arquitetura em seus diversos estilos; das imagens sob variadas tipologias; dos arquivos e demais conjuntos documentais de distintos momentos de nossa história; dos inúmeros bens naturais que devem ser preservados, e das múltiplas formas de festejar, os segredos do saber-fazer, os ritos de uma comunidade.

Neste contexto, o patrimônio arqueológico

[ ] compreende a porção do patrimônio material para a qual os métodos da arqueologia fornecem os conhecimentos primários. Engloba todos os vestígios da existência humana e interessa todos os lugares onde há indícios de atividades humanas, não importando quais sejam elas; estruturas e vestígios abandonados de todo tipo, na superfície, no subsolo ou sob as águas, assim, como o material a eles associados (ICOMOS/ICAHM, 1990, art. $1^{\circ}$ ).

O patrimônio arqueológico constitui-se, portanto, como um testemunho essencial sobre as atividades humanas do passado e pertence a toda a sociedade. Trata-se de uma herança comum da humanidade e de seus grupos, e não exclusivamente de indivíduos ou nações. O patrimônio arqueológico é um recurso cultural frágil e não renovável, de modo que os planos de ocupação de solo decorrentes de projetos desenvolvimentistas devem ser regulamentados a fim de se evitar ou, pelo menos, minimizar a destruição deste patrimônio. 
Sob os domínios da ciência arqueológica, a produção do conhecimento é amplamente tributária da intervenção no sítio. Esta prática abarca uma série de métodos de pesquisa, como a exploração não destrutiva e a escavação integral, passando ainda pelas sondagens limitadas e os levantamentos por amostragem. Neste aspecto, algumas considerações devem ser feitas com relação à natureza metodológica do projeto "Levantamento e Avaliação do Potencial Arqueológico da Serra da Moeda e Entorno".

O primeiro ponto relevante trata-se da representatividade dos vestígios arqueológicos arrolados no que diz respeito ao Patrimônio Arqueológico Total realmente existente na área em questão. $O$ trabalho de levantamento foi realizado tendo como parâmetros, por um lado, as limitações do tempo dentro no qual deveria ser concluído e, por outro, as possibilidades de fontes a serem utilizadas. A grande extensão da área trabalhada inevitavelmente acabou impondo critérios seletivos, que definiram as estratégias do trabalho de campo. A seleção, todavia, foi fundamentada em critérios científicos de significância e representatividade, de modo a não limitar as escolhas apenas aos monumentos de maior prestígio ou visualmente mais sedutores.

Como o trabalho a ser realizado visou a identificação da natureza e das dimensões do patrimônio arqueológico da Serra da Moeda em Minas Gerais, as atividades executadas contemplaram o uso de informações orais, documentais, cartográficas (antigas e recentes) e fotográficas (aéreas e de satélite). Uma pesquisa sistemática em arquivos permitiu o levantamento de uma base documental consistente da qual participaram cartas de sesmarias, testamentos, inventários, censos, dentre outros. A estes tipos de fontes foram incorporadas informações registradas pelos inúmeros viajantes estrangeiros que circularam pela região, desde o século 17 e ao longo de todo o século 19. Por sua vez, o trabalho de campo teve o objetivo de localizar/confirmar a existência de vestígios arqueológicos, bem como realizar seu registro através de diferentes formas como textos, fotos, localização por GPS, etc.

Finalmente, a consolidação das informações permitiu a elaboração de um relatório constituído por um histórico condensado da região seguido das fichas descritivas dos sítios arqueológicos levantados. Estas, por sua vez, contemplaram dados 
singulares de cada sítio como seu nome; localização; registro fotográfico; breve descrição dos elementos estruturais integrantes; o estado de conservação; o ambiente de inserção e do seu entorno, além de outras informações complementares.

Cumpre-se ressaltar que os resultados obtidos não esgotaram 0 potencial arqueológico da região abordada, mas foram apenas uma amostra expressiva do mesmo. O tempo disponível para a realização dos diferentes trabalhos não permitiu que todas as suas possibilidades fossem abarcadas, dadas as dimensões do objeto de pesquisa. $E$ isto remete à necessidade de um trabalho complementar mais amplo com vistas a um conhecimento mais definitivo sobre o patrimônio arqueológico da região objeto de estudo.

Em que pesem tais considerações, o levantamento realizado permitiu uma avaliação bastante objetiva dos vestígios que evidenciam os processos de ocupação da Serra da Moeda e entorno, desde a pré-história até o século 20. A identidade históricocultural das diferentes populações que hoje habitam a região tem, em todos estes vestígios, uma referência imediata e fundamental, o que remete à necessidade de seu conhecimento e preservação. Ainda com relação ao Patrimônio Arqueológico Total, do ponto de vista histórico, há que se considerar o fato de a região em análise ser uma grande unidade que se expressa na integração de suas partes. Tal integração foi produto do processo histórico-cultural e é hoje evidenciada através dos diferentes conjuntos de vestígios arqueológicos.

A ocupação das distintas partes da Serra da Moeda e entorno não se fez de maneira estanque, mas integrada. As diversas comunidades, fazendas, unidades de mineração e núcleos urbanos estavam articuladas através de um complexo e eficiente sistema viário do qual as trilhas e estradas são um consistente indício. As variadas atividades - econômicas e/ou culturais - que articulavam os diferentes elementos daquela realidade, ao longo da história, fazem parte também da tradição oral e dos registros documentais. Tais constatações remetem à necessidade de que a região pesquisada seja vista como uma unidade histórico-cultural e, enquanto tal, seja considerada. 


\section{A Serra da Moeda como uma "unidade histórico-cultural": um conjunto expresso na conexão entre suas partes}

De modo geral, o projeto "Levantamento e Avaliação do Potencial Arqueológico da Serra da Moeda e Entorno" objetivou contextualizar, quantificar e qualificar o patrimônio arqueológico existente no maciço da região em questão. Foram identificados, catalogados e descritos um total de 56 sítios/conjuntos arqueológicos, 5 modelos etnográficos (bens em uso contemporâneo) e 10 áreas com potencial arqueológico (dados obtidos a partir de fontes orais e fotografias aéreas). (1) Do total de 71 ocorrências, apenas 3 (cerca de 4\%) são testemunhos de ocupações préhistóricas, enquanto 68 (aproximadamente 96\%) são remanescentes de assentamentos históricos (cf. Anexo, ao fim deste texto).

Do ponto de vista da pré-história da região, o número ínfimo de ocorrências que se referem a um sítio a céu aberto com sepultamento e a dois abrigos com pinturas rupestres associadas à Tradição Planalto, tais dados indica uma ordem de questões. Dentre elas, constata-se serem até então parcos e superficiais os levantamentos arqueológicos realizados na região da Serra da Moeda e entorno. Destarte, não deve ser rejeitado também os limites impostos pela escassez de informações há muito perdidas pelo processo intenso de ocupação histórica na região.

De qualquer modo, inexistem dados suficientes para a constatação de que nestas paragens houve ou não grande incidência de populações ameríndias. Segundo o pesquisador Oiliam José, antes mesmo da colonização do Brasil pelos portugueses, essa região já era habitada por tribos indígenas de diferentes etnias que pertenciam, com raras exceções, aos grandes grupos Gê e Tapuia. Citam-se os exemplos dos Cataguases ou Cataguás (região central, oeste e sul de Minas), Goianás (vale do Rio das Velhas), Guarachués (entre Mariana, Ouro Preto e Piranga) e os Carijós (Jeceaba e Conselheiro Lafaiete). Muitos topônimos locais se devem a esta influência indígena, como é o caso do Rio Paraopeba que em tupi-guarani significa rio de águas rasas (JOSÉ, 1965, p. 11).

No tocante à conjuntura histórica da região, sabe-se que a ocupação e colonização europeia deram-se a partir de fins do século 17, em função da exploração das jazidas minerais no contexto do denominado "Ciclo do Ouro". Nesta oportunidade, 
esse mineral atraiu toda sorte de aventureiros, degredados e paulistas que penetraram nos sertões das Gerais, terras pertencentes à Capitania do Rio de Janeiro, São Paulo e Minas Gerais. Dentre as primeiras bandeiras que colonizaram a região, cita-se a expedição liderada pelo sertanista Fernão Dias Paes que no ano de 1674, saiu de São Paulo rumo às Minas Gerais com o objetivo duplo de encontrar esmeraldas e de ocupar o território por ele percorrido.

Segundo Augusto de Lima Júnior, apesar de outras bandeiras já terem desbravado as paragens das Minas Gerais, foi a partir da exploração de Fernão Dias que se deu o efetivo povoamento deste território (LIMA JÚNIOR, 1962, p. 19). Os membros das caravanas e outros posseiros, povoadores e demais interessados, estabeleceram-se e construíram ranchos e edificações provisórias que, posteriormente, deram origem aos primeiros núcleos populacionais com suas igrejas permanentes.

Inicialmente, a descoberta do ouro foi o principal fator para o adensamento populacional na região das Minas. Arraiais e núcleos proto-urbanos começavam a se delinear seguindo a topografia irregular do terreno e privilegiando os pontos mais altos da localidade, opção que se deu tanto pelo favorecimento das condições defensivas quanto em respeito à antiga crença católica que acreditava que um segundo dilúvio poderia atingir a Terra. De modo geral, o patrimônio arqueológico e arquitetônico da região e do entorno da Serra da Moeda reflete a influência dos ambientes montanos na implantação e organização dos espaços construídos.

Destacam-se inúmeros povoados e arraiais fundados nas proximidades e arredores da Serra da Moeda que, com o passar dos anos, acabaram se estabelecendo como sedes civil e religiosa da região, a exemplo de Santo Antônio do Rio Acima (Rio Acima), N. Sra. da Boa Viagem da Itabira do Campo (Itabirito), São Gonçalo da Ponte (Belo Vale), N. Sra. da Conceição de Congonhas do Campo (Congonhas) e N. Sra. do Pilar (Ouro Preto). Devem ser ainda mencionadas as cinco comunidades rurais/núcleos urbanos que constaram no levantamento arqueológico, dentre elas os modelos etnográficos de N. Sra. da Piedade do Paraopeba (Brumadinho/MG), N. Sra. da Boa Morte (Belo Vale/MG) e Marinhos da Serra (Belo Vale/MG), além dos extintos conjuntos de Mata da Conceição (Moeda/MG) e Chacrinha dos Pretos (Belo Vale/MG). Estes dois últimos apresentam, por exemplo, vestígios formados por 
alicerces de moradias, capelas, muros e arrimos de pedra, valos, barragens, canais, moinhos e resquícios de lavras. (2)

Consta-se que foi no distrito de Piedade do Paraopeba, um dos primeiros núcleos urbanos formados no território do município de Brumadinho/MG, que a bandeira de Fernão Dias fez o segundo ponto de parada após sair de São Paulo. Ao lado da atual capela dedicada a Nossa Senhora da Conceição existe uma placa alusiva a sua memória que referencia dois episódios: conta tanto sobre a passagem do sertanista pela região na oportunidade em que fundou o arraial no ano de 1674 , quanto faz menção à sua morte que ocorreu nas paragens do Sumidouro (Pedro Leopoldo/MG). Em um documento datado do século 18, há uma descrição que informa que o corpo do bandeirante foi transportado por seu filho até São Paulo onde foi sepultado no mosteiro de São Bento - e, nesta viagem de regresso, um dos pousos teria sido em Santana do Paraopeba.

A fundação, localização e inserção dos povoados e de suas edificações revelam que a presença da Serra da Moeda exerceu significativa influência sobre a caracterização e qualificação desses espaços, uma vez que as localidades tiveram sua implantação influenciada pela conformação do relevo e pelas visadas proporcionadas pela natureza. As igrejas têm sua locação em pontos mais elevados e sempre voltados para as serras, abrindo suas portas para a paisagem e configurando cenários em que o bem natural qualifica e agrega valor aos aspectos culturais locais e aos exemplares de seu acervo arquitetônico.

Além disso, as prospecções arqueológicas reiteraram e, de certa forma, destacaram que a região da Serra da Moeda e de seu entorno, os vales dos rios Paraopeba e das Velhas, expressam a pujança da economia mineral durante os tempos coloniais. Neste caso, os núcleos de mineração levantados no projeto totalizam 21 sítios além de 4 outras áreas com potencial arqueológico - cujo universo representa quase $35 \%$ de todas as ocorrências arroladas. Estes conjuntos oferecem a oportunidade ímpar de estudo sobre os métodos e técnicas minerárias empregadas durante os séculos 18 e 19, uma vez que cada processo extrativo utilizado deixou distintos vestígios. 
A "mineração de cascalho", por exemplo, foi utilizada para a extração do ouro aluvional nos primeiros anos da exploração das jazidas auríferas nas Minas Gerais, de modo que tal técnica está intimamente associada ao emprego de barragens e canais para o desvio das águas do seu curso original. Após este procedimento, os escravos revolviam o leito do rio utilizando almocafres e alavancas para, na seqüência, os sedimentos com potencial mineral serem apurados nas bateias.

Por outro lado, a "mineração de morro" explorava as jazidas auríferas presentes nas formações rochosas de encostas. Esta exigia técnicas mais apuradas e, portanto, maior investimento no processo de extração mineral, de modo que era praticada apenas pelos mais ricos mineiros. Estão associadas a este procedimento as catas de talha a céu aberto, método que consistia em abrir fendas nas rochas, do cume até sua base, para que então com o uso de força humana e/ou hidráulica fossem extraídos os sedimentos. São comumente associados a este procedimento estruturas como tanques, mundéus e canais (GUIMARÃES; REIS, 2007).

Neste contexto, deve ser mencionado o sítio arqueológico denominado de Forte de Brumadinho (Brumadinho/MG) como um típico representante das unidades mineradoras da primeira metade do século 18. Implantado em posição geograficamente privilegiada, na encosta oeste da Serra da Calçada, é constituído por uma fortificação, uma grande cata a céu aberto, um extenso sistema hidráulico e uma estrada calçada que ligava a área de lavra, na parte mais baixa, ao topo da Serra. Admite-se, que o conjunto imediato do Forte define apenas o núcleo central da atividade minerária, uma vez que em uma perspectiva mais ampla, contemplamse outros vários pontos desta região serrana como locais onde o ouro setecentista marcou sua presença.

Outro sítio arqueológico relacionado à dinâmica da mineração colonial e que merece menção são as ruínas de São Caetano da Moeda (Moeda/MG). Trata-se do conjunto de vestígios da antiga Casa de Moeda Falsa do Paraopeba, também conhecida por Fábrica do Paraopeba, uma fundição clandestina de moedas de ouro localizada nos contrafortes da até então chamada Serra do Paraopeba. Tal sítio arqueológico reflete o contexto do rigor tributário do setecentos em oposição à constituição de uma "cultura da sonegação" contra o imposto do quinto, ocasião da introdução de 
normas mais rígidas com a finalidade de aumentar a arrecadação e de tornar mais efetiva a presença da Coroa na região.

Indícios documentais confirmam a presença, entre os anos de 1729 e 1732, da Casa de Moeda Falsa do Paraopeba nos contrafortes da Serra da Moeda especificamente localizada no povoado de São Caetano da Moeda - cuja fortificação foi responsável pela origem do atual topônimo da Serra da Moeda. Cabe ressaltar que a moeda ali produzida foi chamada de falsa pelo fato de que o ouro não era fundido ou quintado nas Casas de Fundição Reais e, portanto, as barras não recebiam o selo da Coroa portuguesa que legalizava a sua circulação depois de cobrado o devido imposto (VEIGA, 1998, p. 753. v. 4).

Desde o início, o empreendimento liderado por Ignácio José de Souza Ferreira que tinha Francisco Borges de Carvalho como sócio, exigiu grandes investimentos tanto em relação à infraestrutura quanto na composição da equipe formada por outros comparsas e "numerosa escravatura". As instalações da Fábrica contavam, além da própria casa de fundição, com casas de vivenda, cozinha, senzala, ferraria, carvoaria, olaria, engenho de pilões, ranchos de vigia, açude, pontes e uma igreja dedicada a São Caetano. No tocante à equipe, o grupo contava com a participação de aproximadamente duas dezenas de homens livres e um plantel que reunia em torno de cinquenta escravos.

Dentre os vestígios encontrados pelo levantamento arqueológico, o local apresenta uma estrutura fortificada e diversos muros de pedras. A edificação principal, em partido quadrangular, apresenta vãos de seteiras para todos os lados, fato que indica ser esta construção uma unidade defensiva. No entorno imediato existem muros de pedras que delimitavam áreas para criação de porcos e gado, de modo a demonstrar que a ocorrência de núcleos de mineração também expressa uma imbricada conexão com as atividades agropastoris e comerciais.

Assim, não se desconsidera o fato de, apesar da mineração ter sido o que se convencionou chamar de atividade nuclear, a economia da sociedade mineira colonial foi pautada pela diversidade na medida em que a própria mineração exigia o respaldo da agricultura, da pecuária e de um grande número de outras atividades 
que eram sustentadas pela mão-de-obra escrava. Por sua vez, a diversificação esteve presente não só no plano econômico, mas também na estrutura social, uma vez que diferentes categorias sociais definidas por um amplo leque de qualidades e condições interagiam e se interpenetravam, dando o tom a um contexto social extremamente dinâmico e permeado de conflitos.

A constituição de unidades voltadas à produção alimentar, portanto, não impediu que muitas lavras se desenvolvessem integradas às fazendas dedicadas ao cultivo dos gêneros necessários ao provimento das minas e ao consumo interno. A prospecção arqueológica levantou, neste caso, 9 vestígios de propriedades rurais, além de 6 edificações caracterizadas como modelos etnográficos e 1 área com potencial arqueológico, o que contabiliza cerca de $22 \%$ do total arrolado. Tais sítios oferecem a possibilidade de um estudo arqueológico aprofundado sobre 0 funcionamento e a vida cotidiana das fazendas na época colonial e imperial. A organização do espaço; as técnicas construtivas e tecnologias empregadas para a exploração e produção dos meios de subsistência; além dos hábitos de consumos dos diferentes grupos que moravam na fazenda, por exemplo, podem ser temas analisados a partir da cultura material/vestígios arqueológicos que se encontram preservados. A este aspecto deve ser acrescentada a implantação das fazendas e sua inserção na dinâmica regional, matérias que também podem ser contempladas pelas pesquisas arqueológicas, históricas e arquitetônicas.

Neste contexto, deve ser mencionada a Fazenda das Contendas, propriedade localizada ao sul da freguesia de São Caetano da Moeda nas proximidades do arraial de N. S. da Boa Morte (Belo Vale/MG). Pesquisas indicam que esta Fazenda que foi construída a pedido do chamado "Doutor das Contendas" - homem diplomado em Agricultura na França - teria abastecido com uma profusão de mantimentos a Vila Real de Ouro Preto. Seus proprietários, o Capitão Simeão Ribeiro de Carvalho e sua esposa Joana Tereza de Oliveira, deixaram apenas um herdeiro que se tornou, em fins do século 18, o dono da Fazenda das Contendas.

Este se tratava do Padre Silvério Ribeiro de Carvalho - mais conhecido pela corruptela de Padre Silvério do Paraupeba [sic], Silvinho Paraopeba ou ainda Vigário do Paraopeba - que nasceu em Itabira do Campo (atual município de Itabirito) no ano de 1767 e faleceu em São Caetano da Moeda em maio de 1843. Segundo 
informações orais, após a sua morte, a Fazenda das Contendas foi elevada a hasta pública, com seus bens revertidos em benefício de instituições religiosas de caridade e os escravos alforriados. Tais dados, todavia, não foram comprovados pela documentação histórica levantada.

O Padre Silvério Ribeiro de Carvalho foi apresentado pelo historiador Diodo de Vasconcelos como sendo "fazendeiro e minerador", mas sabe-se que ele também se inseriu no universo religioso e das letras (VASCONCELLOS, 1896, p. 449). No ano de 1799, quando o Vigário já detinha sua herança, a Fazenda das Contendas possuía um terreno avaliado em torno de 550 alqueires dedicados à produção de gêneros como a farinha de mandioca, o fubá de milho, a aguardente, além da criação de animais.

Em 1831, a Fazenda das Contendas foi descrita como sendo dedicada à "cultura da terra", onde "49 pessoas livres e 80 cativos", fundamentalmente do sexo masculino, empregavam-se na agricultura, de modo que as mulheres se ocupavam dos serviços da casa como "coser, fiar e tecer". Tomando como referência o distrito ao qual pertencia - São Caetano da Moeda que possuía 112 domicílios e 839 habitantes somente a Fazenda das Contendas formada por 129 moradores detinha 15\% da população de todo o arraial. Além disso, merece destaque a grande quantidade de escravos - 80 cativos -, ou seja, aproximadamente $19 \%$ do conjunto de 426 negros existentes em São Caetano da Moeda. (3)

Atualmente, restam apenas as ruínas da sede formada por uma base de pedras que servia de alicerce da casa assobradada. No primeiro pavimento, possivelmente existiam dois cômodos utilizados como estribaria e paiol e, no segundo, havia a habitação propriamente dita. A estrutura de pedras do primeiro pavimento apresenta um corredor central, ladeado por dois cômodos, que possui dois vãos para portas com ombreiras e vergas feitas com pedra lavrada em cantaria. Os cômodos laterais apresentam vãos para portas com as mesmas características e cujas janelas, dispostas no lado posterior, são de pequeno porte, em formato quadrado e gradeadas com madeira ainda preservada. 
Observa-se que, com o passar dos anos, as vastas extensões das propriedades rurais do século 18 e meados do 19, fragmentavam-se cada vez mais na medida em que o cabedal das linhagens foi repartido entre seus diversos herdeiros e a mão-deobra escrava se tornou mais escassa. Constata-se que a partir das sedes destas fazendas, instalaram-se no seu entorno outras unidades produtivas de porte menor, templos religiosos destinados aos cultos comunitários, pequenos comércios, etc. Estes locais acabaram dando origem, paulatinamente, a povoados, arraiais, distritos e municípios, de modo a também incentivar a abertura de caminhos que ligavam aquelas unidades produtivas aos centros consumidores, a exemplo de Ouro Preto. Nestas estradas foram instalados retiros com vastos currais, pousos de descanso para tropeiros e boiadas após enfrentarem longas jornadas de viagens.

Neste caso, os caminhos e estradas levantadas pelo projeto totalizam 5 sítios, além de 3 outras áreas com potencial arqueológico, cujo universo representa cerca de $12 \%$ de todas as ocorrências arroladas. Esclarece-se que estas estradas podem ser classificadas, de modo geral, em dois grupos: aquelas chamadas de "carroçáveis", dotadas de pedras mais largas que traçavam um caminho onde os carros de bois ou carroças poderiam seguir; e as "cavaleiras" ou "canjicadas", cujos trechos estritos demarcados por pedras irregulares eram destinados apenas às tropas de animais.

Deve ser sublinhado o fato de que o estudo dos antigos sistemas viários coloca-se como condição básica para a compreensão da dinâmica das sociedades colonial e imperial. A Serra da Moeda, por sua proximidade com o sistema denominado "Estrada Real", apresenta um grande conjunto de segmentos de diversos tipos como trilhas de pedestres, estradas cavaleiras, tropeiras e carroçáveis, com estruturas arrimadas, calçamentos e galerias pluviais.

Com a crise da extração mineral a partir de princípios da segunda metade do século 18, outras atividades econômicas até então colocadas em segundo plano passaram a ocupar espaços cada vez maiores na dinâmica colonial. É nesse contexto que a extração e o processamento do ferro passou a ser uma formidável fonte de riquezas, integrando o que foi denominado por alguns autores de proto-industrialização da Capitania de Minas Gerais. 
Na esteira destas transformações, em 1811, o Coronel Romualdo José Monteiro de Barros, proprietário da Fazenda Boa Esperança localizada no povoado de N. S. da Boa Morte, juntou-se ao grupo de dez sócios liderado pelo engenheiro alemão Wilhelm Ludwig (Barão de Eschwege) para criar a Fábrica de Ferro do Prata também chamada de Fábrica de Ferro de Congonhas do Campo ou Usina Patriótica. Fundada no ano seguinte, a Usina continha oito fornos de fundição, duas fornalhas para forja, depósitos, cozinha e sistema de abastecimento hidráulico, além de uma senzala e casa de administração.

Várias destas estruturas em ruínas, dispersas nas proximidades do Córrego da Prata, foram identificadas pela prospecção arqueológica. A implantação da Usina Patriótica foi feita na margem direita do curso d'água, de modo a atender as necessidades hídricas da Fábrica, a exemplo do uso de um britador e de um malho hidráulico. Observa-e que as estruturas foram feitas com pedras tipo canga e paredes revestidas com reboco. Existem algumas plataformas arrimadas para 0 nivelamento do terreno e escadas para acesso aos diversos níveis.

Do ponto de vista histórico e arqueológico, este sítio se reveste de enorme importância na história da siderurgia no Brasil dado que foi o primeiro empreendimento do gênero a funcionar eficazmente em escala industrial para a produção de ferro em Minas Gerais. Tal relevância é suficiente para justificar o fato deste sítio arqueológico ter sido protegido pelo IPHAN no ano de 1937, quando do início da aplicação da Lei do Tombamento. Além disto, a Fábrica de Ferro do Prata tem sua importância histórica associada à figura de Wilhelm Ludwig von Eschwege, construtor da Fábrica de Ferro do Prata e empreendedor de diversas atividades ligadas à pesquisa e produção mineral na região do atual Quadrilátero Ferrífero.

A produção de minério de ferro em escala industrial, iniciada com a experiência da Fábrica de Ferro de Congonhas do Campo, insere-se no contexto que tornou viável o desenvolvimento das linhas ferroviárias no Brasil. Tais implementos foram responsáveis, em grande medida, pela transformação radical das formas de se praticar o comércio e o transporte nas Minas Gerais que, até aquele momento, eram feitos em caminhos e estradas de terra em carros de bois e lombos de animais. Com a propagação das estradas de ferro pelo Brasil a partir de 1869 e, no caso da 
Província de Minas Gerais com a fundação da linha Oeste de Minas no ano de 1880, inúmeras localidades voltadas à agricultura se desenvolveram em ritmo acelerado, a exemplo das paragens localizadas no vale do Rio Paraopeba.

O incremento da industrialização do ferro iniciada pela Usina Patriótica, que resultou na implantação do sistema ferroviário no Brasil, determinou a alteração do papel predominante que os caminhos da Serra da Moeda possuíam até então, e gerou o surgimento de estações ferroviárias e fundação de novas cidades implantadas ao redor destas paradas. Este foi o caso, por exemplo, da sede do município de Moeda/MG ou da Estação de Arrojado Lisboa.

À guisa de conclusão cumpre-se ressaltar que o painel histórico e o esboço arqueológico apresentados são apenas uma amostragem da imensa riqueza do processo de ocupação da Serra da Moeda e de seu entorno. Tal opulência se expressa de forma inequívoca na imensa quantidade de vestígios arqueológicos de diferentes tipos e épocas que se encontram espalhados por toda a região. A Serra da Moeda e seu entorno se apresentam como "unidade histórico-cultural", ou seja, um conjunto expresso na conexão entre suas partes por diversas questões apresentadas ao longo deste texto e observado, ainda, pelo elo estabelecido entre o passado e o presente que testemunha a continuidade das práticas minerárias, agropastoris e siderúrgicas na região.

\section{Anexo - Listagem dos sítios levantados durante os trabalhos de prospecção arqueológica na região da Serra da Moeda/MG e entorno}

\section{- Sítios Arqueológicos:}

. Fazenda Morro Velho e Pedro Paulo (Retiro da Pedras/Brumadinho/MG).

- Núcleo de Mineração do Córrego Morro Velho e Pedro Paulo (Retiro da Pedras/Brumadinho/MG).

. Abrigo do Retiro das Pedras (Retiro da Pedras/Brumadinho/MG).

. Núcleo de Mineração Retiro das Pedras I (Retiro da
Pedras/Brumadinho/MG).
. Núcleo de Mineração Retiro das Pedras II (Retiro da
Pedras/Brumadinho/MG).


. Muros do Córrego Bernardino (Retiro da Pedras/Brumadinho/MG).

Núcleo de Mineração do Córrego Bernardino (Retiro da Pedras/Brumadinho/MG).

Núcleo de Mineração do Ribeirão da Catarina (Casa Branca/Brumadinho/MG).

. Abrigo do Ribeirão da Catarina (Casa Branca/Brumadinho/MG).

Núcleo de Mineração do Forte de Brumadinho (Casa Branca/Brumadinho/MG).

. Núcleo de Mineração do Córrego Senzala I (Casa Branca/Brumadinho/MG).

. Núcleo de Mineração do Córrego Senzala II (Casa Branca/Brumadinho/MG).

. Estrada Cavaleira da Serra da Calçada (Casa Branca/Brumadinho/MG).

- Núcleo de Mineração do Córrego Fundo/Tutaméia I (Casa Branca/Brumadinho/MG).

- Núcleo de Mineração do Córrego Fundo/Tutaméia II (Casa Branca/Brumadinho/MG).

- Núcleo de Mineração do Córrego Fundo/Tutaméia III (Casa Branca/Brumadinho/MG).

. Núcleo de Mineração Pau Branco (Casa Branca/Brumadinho/MG).

. Núcleo Urbano de Piedade de Paraopeba (Suzana/Brumadinho/MG).

. Estrada Cavaleira Beira Serra (Beira Serra-Suzana/Brumadinho/MG).

. Habitações Rurais Beira Serra (Beira Serra-Suzana/Brumadinho/MG).

. Igreja Velha de Suzana (Suzana/Brumadinho/MG).

. Núcleo de Mineração Água Limpa I (Água Limpa//tabirito/MG).

. Núcleo de Mineração Água Limpa II (Água Limpa/ttabirito/MG).

. Núcleo de Mineração Água Limpa III (Água Limpa/ltabirito/MG).

. Fazenda Lagoa das Codornas (Represa das Codornas/Rio Acima/MG).

. Mineração Cata Branca (Cata Branca/ltabirito/MG).

. Fazenda Aredes (Aredes/Itabirito/MG).

. Núcleo de Mineração Aredes (Aredes/ltabirito/MG).

. Muro e Valos da Serra em São Caetano (Trevo na BR-040 que segue para Moeda/ltabirito/MG).

. Sítio Pedra Negra (Itabirito-Moeda/MG).

. Ruínas da Serra de São Caetano (São Caetano da Moeda/Moeda/MG).

. Estrada Carroçável de São Caetano (São Caetano da Moeda/Moeda/MG). 
- Comunidade Rural da Mata da Conceição (São Caetano da Moeda/Moeda/MG).

. Ruínas de São Caetano da Moeda (São Caetano da Moeda/Moeda/MG).

. Fazenda da Cachoeira (Moeda Velha/Moeda/MG).

. Fazenda Contendas (Contendas/Moeda/MG).

. Muro de Pedras do Córrego Pedra Vermelha (Pedra Vermelha/Moeda/MG).

. Habitação Rural da Grota dos Antunes (Grota dos Antunes/Moeda/MG).

. Estrada Cavaleira da Grota dos Antunes (Grota dos Antunes/Moeda/MG).

- Muro de Pedras do Mirante da Serra (BR-040 na Parada Mirante da Serra/ltabirito/MG).

. Núcleo de Mineração Saboeiro (Saboeiro/Itabirito/MG).

. Núcleo Urbano Marinho da Serra (Marinho da Serra/Moeda/MG).

. Fazenda dos Azevedo (Marinho da Serra/Moeda/MG).

. Fazenda da Barra (Barra do Gentio/Moeda/MG).

. Pouso do Belvedere (Belvedere-Viaduto Vila Rica/Itabirito/MG).

. Usina Patriótica (Ferteco/Ouro Preto/MG).

. Fazenda Fortificada da Lagoa Velha (Ouro Preto/MG).

. Galeria de Mineração da Serra dos Mascates (Boa Morte/Belo Vale/MG).

. Estrada Carroçável da Serra dos Mascates (Boa Morte/Belo Vale/MG).

- Muro de Pedras da comunidade de Boa Morte (Ribeirão dos Paiva ou Pedra/Belo Vale/MG).

. Núcleo Urbano de Boa Morte (Boa Morte/Belo Vale/MG).

. Sítio Pré-Histórico da Fazenda dos Paiva (Ribeirão dos Paiva ou Pedra/Belo Vale/MG).

. Sítio Arqueológico e Comunidade Chacrinha dos Pretos (Chacrinha dos Pretos/Belo Vale/MG).

. Estação Ferroviária Arrojado Lisboa (Arrojado Lisboa/Belo Vale/MG).

. Fazenda do Barão (Arrojado Lisboa/Belo Vale/MG).

- Habitação Rural no Pé da Serra do Esmeril (Serra do Esmeril/Belo Vale/MG).

- Modelos Etnográficos/Patrimônios Edificados:

. Fazenda Gordura (Piedade do Paraopeba/Brumadinho/MG).

. Fazenda da Grota (Porto Alegre/Moeda/MG). 


\section{. Fazenda Boa Esperança (Boa Morte/Belo Vale/MG). \\ . Fazenda Santa Cecília (Chacrinha dos Pretos/Belo Vale/MG). \\ . Fazenda Córrego da Areia (Arrojado Lisboa/Belo Vale/MG). \\ . Fazenda Santa Cruz (Arrojado Lisboa/Belo Vale/MG).}

\section{- Área com potencial arqueológico:}

. Estrada Cavaleira da Serra de Ouro Fino (Casa Branca/Brumadinho/MG).

. Caminhos na Serra em Suzana (Suzana/Brumadinho/MG).

. Fazenda de Suzana (Suzana/Brumadinho/MG).

. Núcleo de Mineração do Córrego Mina D’água (Aredes/ltabirito/MG).

. Núcleo de Mineração do Córrego da Lagoa Seca (Aredes/ltabirito/MG).

. Núcleo de Mineração do Córrego Carioca (Córrego do Bação/ltabirito/MG).

- Núcleo de Mineração do Córrego das Serrinhas (Córrego do Bação/ltabirito/MG).

. Estrada Cavaleira da Serra das Almas (Serra das Almas/Moeda/MG).

. Muro de Pedras da Fazenda da Barra (Moeda/MG).

. Muro de Pedras da Fazenda Santo Antônio (Ribeirão dos Paiva ou Pedra/Moeda/MG).

\section{Notas}

(1) Deve ser sublinhado que durante os trabalhos de prospecção arqueológica foram identificadas inúmeras fazendas antigas ainda em atividades. Tais edificações foram registradas como modelos etnográficos na medida em que sua análise pode fornecer informações importantes para a compreensão dos sítios arqueológicos remanescentes de antigas fazendas similares. Por outro lado, a condição/contexto de origem destas fazendas coloca-as na categoria de patrimônio histórico edificado que deve ser objeto de estudo e preservação/restauração.

(2) O núcleo de Chacrinha dos Pretos (Belo Vale/MG) é um caso exemplar do processo de apropriação contemporânea das ruínas de um espaço arqueológico. É um sítio caracterizado pela implantação de uma comunidade de afro-descendentes em uma área onde estão os vestígios de uma grande e antiga fazenda, constante também de uma capela e de outras edificações menores.

(3) Relação dos habitantes do distrito de São Caetano da Moeda, termo da cidade de Ouro Preto. 1831. Microfilme 01, caixa 01, documento 02. Coleção Mapas de População pertencente ao acervo do Arquivo Público Mineiro (APM). 


\section{Referências bibliográficas}

CAMPOS, Luana Carla Martins Campos. Vou te contar... Café com Histórias - Viajando no tempo: um pouco da história da Fazenda Boa Esperança em Belo Vale/MG. Tribuna - Jornal da ASMAP, Brumadinho, MG, n. 46. Caderno Por Dentro do Vale, n. 8, out. 2009. p. 04.

Disponível em: http://www.brumadinhotour.com.br/pordentrodovale/cafecomhistoriafazendaboaesperanca.php. Acesso em: 15 de jan. 2011.

CAMPOS, Luana Carla Martins Campos. Vou te contar... Café com Histórias - Mas por qual motivo a Serra da Moeda possui este nome? Tribuna - Jornal da ASMAP, Brumadinho, MG, n. 47. Caderno Por Dentro do Vale, n. 9, nov. 2009. p. 04.

Disponível em: http://www.brumadinhotour.com.br/pordentrodovale/cafecomhistoriaserradamoeda.php. Acesso em: 1 nov. 2010.

CAMPOS, Luana Carla Martins Campos. Vou te contar... Café com Histórias - Entre boatos e lendas: as ruínas do Forte de Brumadinho. Tribuna - Jornal da ASMAP, Brumadinho, MG, n. 49. Caderno Por Dentro do Vale, n. 11, jan. 2010. p. 04.

Disponível em: http://www.brumadinhotour.com.br/pordentrodovale/cafecomhistoriaruinasfortebrumadinho.php. Acesso em: 8 jan. 2011.

CANCLINI, Néstor García. O patrimônio cultural e a construção imaginária do nacional. Revista do Patrimônio Histórico e Artístico Nacional: Cidades, organização de Heloísa Buarque de Hollanda, Rio de Janeiro, n. 23, p. 95-115, 1994.

DE CERTEAU, Michel. Andando na cidade. Revista do Patrimônio Histórico e Artístico Nacional: Cidades, organização de Heloísa Buarque de Hollanda, Rio de Janeiro, n. 23, p. 21-31, 1994.

GUIMARÃES, Carlos Magno et al. Projeto arqueológico de prospecção e topografia do Forte de Brumadinho e Entorno. Belo Horizonte: Laboratório de Arqueologia da Fafich/UFMG, 2002.

GUIMARÃES, Carlos Magno; REIS, Flávia Maria da Mata. Agricultura e mineração no século XVIII. In: RESENDE, Maria Efigênia Lage de; VILLALTA, Luiz Carlos (Orgs.). As Minas setecentistas. Belo Horizonte: Companhia do Tempo; Autêntica, 2007. p. 321-335. (História de Minas Gerais, 2).

GUIMARÃES, Carlos Magno; ZARANKIN, Andrés; CAMPOS, Luana Carla Martins; PEREIRA, Anderson Barbosa Alves. Patrimônio arqueológico da Serra da Moeda e Entorno. In: SOLÁ, Maria Elisa Castellanos; GUIMARÃES, Carlos Magno; PAIVA, José Eustáquio Machado de (Orgs.). Patrimônio natural-cultural e zoneamento ecológicoeconômico da Serra da Moeda: uma contribuição para sua conservação. Belo Horizonte: Brandt Meio Ambiente, 2008. p. 157-348. v. 1.

HALL, Stuart. A identidade cultural na pós-modernidade. 11. ed. Rio de Janeiro: DP\&A, 2006.

ICOMOS/ICAHM. Carta de Lausanne. Carta para a proteção e a gestão do patrimônio arqueológico. 1990.

Disponível em: http://portal.jphan.gov.br/portal/baixaFcdAnexo.do?id=262. Acesso em: 20 nov. 2009. 
JOSÉ, Oiliam. Indígenas de Minas Gerais: aspectos sociais, políticos e etnológicos. Belo Horizonte: Edições Movimento-Perspectiva, 1965.

LIMA JÚNIOR, Augusto de. As primeiras vilas do ouro. Belo Horizonte: Gráfica Santa Maria, 1962.

PESAVENTO, Sandra Jatahy. História \& história cultural. 2. ed. Belo Horizonte: Autêntica, 2008. (Coleção História \&...Reflexões, 5).

SOLÁ, Maria Elisa Castellanos; GUIMARÃES, Carlos Magno; PAIVA, José Eustáquio Machado de (Orgs.). Patrimônio natural-cultural e zoneamento ecológico-econômico da Serra da Moeda: uma contribuição para sua conservação. Belo Horizonte: Brandt Meio Ambiente, 2008. 2 v.

VASCONCELLOS, Diogo Pereira Ribeiro de. Parte inedita da monographia do Dr. Diogo Pereira Ribeiro de Vasconcellos sobre a Capitania de Minas-Geraes, escripta no primeiro decenio do presente século. Revista do Arquivo Público Mineiro, v. 01, p. 443-452, jul./set. 1896.

VEIGA, José Pedro Xavier da. Efemérides mineiras: 1664-1897. Belo Horizonte: Fundação João Pinheiro, 1998. $4 \mathrm{v}$.

YÚDICE, George. A conveniência da cultura: usos da cultura na era global. Belo Horizonte: Editora UFMG, 2004.

\section{Crédito}

* Licenciada e Mestre em História (UFMG), com formação complementar em Antropologia e Arqueologia pela mesma instituição. Atua no campo da gestão do patrimônio cultural e arqueologia histórica, tendo realizado diversas consultorias e assessorias técnicas em ICMS Cultural e Licenciamento Ambiental. Possui experiência com fontes iconográficas com destaque em suas pesquisas para a cultura visual, material e história da fotografia. Também é educadora dedicada a trabalhos em educação patrimonial e confecção de materiais didáticos. e-mail: luanacmc1@hotmail.com. 